\title{
Effectiveness of Positive Reinforcement to Improve Discipline through Caregiver
}

\section{Salsabila Mayang Sari ${ }^{\mathrm{a}}$ and Wahyu Indianti ${ }^{\mathrm{b}}$}

${ }^{a}$ Department of Educational Psychology, Faculty of Psychology, Universitas Indonesia, Depok, Indonesia; ${ }^{b}$ Department of Educational Psychology, Faculty of Psychology, Universitas Indonesia, Depok, Indonesia

*Corresponding Authors:

Wahyu Indianti

Department of Educational Psychology, Faculty of Psychology, Universitas Indonesia Jl. Lkr. Kampus Raya, Depok, Jawa Barat Indonesia, 16424

Tel.: +62 217270004

Email: wahyu.indianti@ui.ac.id 


\title{
Effectiveness of Positive Reinforcement to Improve Discipline through Caregiver
}

\begin{abstract}
The aims of this research are to investigate the effectiveness of positive reinforcement to improve discipline behavior in a kindergarten student. The discipline behavior is important as a key success of school readiness and future academic success. Children will not be able to adapt to academic tasks and social interactions at school if they have disciplinary problems. This intervention is a single case study $(\mathrm{N}=1)$ applied in a home setting. This method used pre-post design (AB design) and multiple baseline across settings (eating and playing situation). A caregiver implements this intervention in home settings because children spend most of their time with a caregiver while parents are working. This intervention was 18 days and includes a baseline phase, intervention, and evaluation phase. The result proves that positive reinforcement is effective to improve discipline behavior in home settings (eating and playing situation). This research also found that measures to improve discipline in children can be implemented by a caregiver.
\end{abstract}

Keywords: positive reinforcement, discipline, intervention, caregiver

\section{Introduction}

School is a crucial place for children aged 3 to 5 years because it becomes a second environment to develop their abilities. Children start to learn by adapting to the rules applied in school, such as understanding the rules, recognizing the consequences, being responsible for the task, maintaining concentration, and interaction with peers (Santrock, 2011). The child's ability to adapt to the rules applied supports their readiness for school and future academic success.

The success of children in school is also influenced by how they are treated by the significant people in their lives. The learning process for children is not limited to school and includes the home. The treatment and parenting style of parents significantly influences children's learning attitudes at school. Parents are responsible for forming the children's regulations and selfcontrol in the home setting, and these can be taught by giving direction, regulation, warmth, and stimulation through activities at home (Santrock, 2011). Otherwise, their self-adjustment behavior and discipline at school can be affected, especially when children are not used to regulating and controlling themselves at home (Lansford et al., 2010; Michels et al., 1993).

Discipline is a behavior that has to be adapted by using applied regulations in the environment (Nieman et al., 2004). Discipline is a child's actions in various situations. Children will be able to be disciplined if they can make a distinction between good and bad behavior in the environment. In the preschool stage, the stimulation of discipline behavior begins by creating a disciplined environment. In the stage of development where concrete conceptual thinking begins, children need a direct direction from the significant people in their lives to learn discipline behavior. The key concepts to teach discipline in children are clear rules, effective consequences, and consistent implementation. This process can be started from fundamental 
behaviors at home, such as eating, playing, bathing, sleeping, and doing school work (Phelan, cited in Bowman, 2013). Those fundamental behaviors can be measured as children's discipline habits at home.

Regarding teaching discipline at home, the role of parents can be replaced by caregivers. A caregiver is a person who has a close relationship and replaces the role of parents while they work (WHO, 2004). Caregivers can be a significant role model for children' daily behavior because caregivers may spend more time with the children than their parents. How a caregiver implements discipline can be reflected by the parenting style applied (Feldman \& Klein, 2003)? Caregivers who implement positive discipline teach children by explaining the reasons for performing a behavior. By contrast, using negative discipline teaches children to obey and refuse punishment (Smith, 2004). Thus, caregivers can play a critical role in creating the discipline behavior.

One intervention technique to shape behavior is behavior modification. Behavior modification has been proven effective in the literature and has been used as an effective treatment for changing children's behavior. Behavior modification is a technique to increase and shape a desirable behavior in a structured environment (Miltenberger, 2016). Some researchers have investigated behavior modification to increase desirable behaviors such as on-task behavior (Nasa, Pudjiati, \& Tjakrawiralaksana, 2018) and compliance (Kusumah \& Pudjiati, 2017) with or without specific disorders (Carter, 2010). One behavior modification technique is positive reinforcement.

Positive reinforcement is giving a reinforcer to strengthen the targeted behavior (Miltenberger, 2016; Martin \& Pear, 2015). Some research has found that positive reinforcement provides internal motivation and clear expectations for children's behavior (Ma, 2010; Wilder, 2005). Applying positive reinforcement helps children comprehend adult expectations and behave appropriately in an environment.

The essential element of positive reinforcement is that the occurrence of the targeted behavior is followed by a reinforcer, and the result is strengthening the targeted behavior (Martin \& Pear, 2015). A reinforcer is an object or event that can influence the behavior of a person. The reinforcer is effective when given immediately after the targeted behavior is exhibited, and the type of reinforcer is effective to strengthen the behavior. Positive reinforcers vary and may include something pleasant, valuable, and desirable that a person would want to receive.

The effective application of positive reinforcement is required to select the specific behavior to be increased (Martin \& Pear, 2015). The specific behavior must have indicators that can be evaluated. Moreover, it must be possible to control the behavior by using a natural reinforcer in the setting. An effective reinforcer is readily available, feasible, appropriate, can be presented immediately, can be used over again, and does not require time to consume. In applying positive reinforcement, the researcher must tell the participant about planning and the consequence. 
This research aims to investigate the effectiveness of positive reinforcement on a kindergarten student with low discipline behavior. This case came from one private school in the Jakarta area. The nondiscipline behavior consists of arriving late, play outside during study time, and not finishing tasks. The school was implementing discipline strategies, but the discipline behavior remained inconsistent. This result indicates undisciplined behavior with a caregiver at home. Therefore, applying positive reinforcement carried out by a caregiver in a home setting is essential to improving discipline behavior in a home setting through eating and playing situations. Both of these situations are primary conditions at home.

\section{Methods}

\section{Participants}

The participant in this case study was NA, a boy aged 4 years 5 months. NA had an average level of intelligence (IQ = 107, Wechsler Scale) and problems with regulating his disciplinary behavior in learning situations at kindergarten A, such as not obeying the class rules, not sitting quietly during the learning process, not completing tasks, and engaging in many nondirected playing activities. Those behaviors are habits that he usually acts out at home with his caregiver, EN. The class teacher complains that NA often associates his habits at school with his habits at home with the caregiver. EN is a 56-year-old woman, and her highest level of education was junior high school.

\section{Research Design}

This study used a case study with an $A B$ design. A single case study is applied to studies that use one or small groups of participants. $A B$ design is used to evaluate differences between before and after the intervention was carried out (Gravetter \& Forzano, 2012). This design has the following advantages: time flexibility, time efficiency, and ease of application in natural settings (Fraenkel \& Wallen, 2009). In addition, this study uses multiple baselines to explain the effects of the intervention on two target behaviors. The two behaviors measured are called eating behavior and playing behavior. The evaluation of these two behaviors started on the same day but at different times. Eating behavior was measured in the morning and afternoon, and playing behavior was assessed in the afternoon.

\section{Measurement}

The instruments for positive reinforcement measurement used in this study were the reinforcement questionnaire and the observing and recording sheet. The reinforcement questionnaire was adapted from Martin and Pear (2015) and used to determine the most effective type of reinforcement to change a child's behavior. The selection of reinforcement was used as a reward to form consistency regarding the child's behavior. The observing and recording sheet was developed based on a sheet from Miltenberger (2016). This sheet was used to record the appearance of the behaviors in the baseline, intervention, and evaluation phases. Based on this recording, we calculated the percentage of successful discipline in the child on a daily basis. 
To measure the increase in the frequency of the eating behavior and play behavior on the observing and recording sheet, we used the following calculation.

Total score of expected behaviors

$\mathrm{x} 100 \%$

Total score of displayed behaviors

\section{Procedure}

Before the intervention was carried out, the researcher asked for permission from the school, parents, and caregiver. The researcher explained the procedure of the intervention program and the duration of the intervention implementation. Next, the school, parents, and caregiver signed an informed consent form.

Before the intervention, researchers began by performing a functional behavioral assessment to find out the specific behavior that would be given through an intervention. This process was conducted through observations and an interview with the caregiver when she was with the children at home. With this assessment, we aimed to find out how caregivers communicate to deliver information and instructions to children. The measurement of disciplinary behavior was focused on the child's eating behavior and playing behavior. Table 1 is an overview of the functional behavioral assessment results from the results of this study.

Table I. Functional Behavioral Assessment

\begin{tabular}{|c|c|c|c|}
\hline Targeted Behavior & Antecedents & Behavior & Consequences \\
\hline Meal behavior & \begin{tabular}{ll} 
Verbal & \multicolumn{2}{r}{ command } \\
was given by \\
caregiver
\end{tabular} & $\begin{array}{l}\text { Deficit of complaint } \\
\text { behavior (Function: } \\
\text { Avoidance/Rejection) }\end{array}$ & $\begin{array}{l}\text { Child did not comply with the } \\
\text { command and went away }\end{array}$ \\
\hline Play behavior & $\begin{array}{l}\text { Child played with } \\
\text { his toys }\end{array}$ & $\begin{array}{l}\text { Deficit of complaint } \\
\text { behavior (Function: } \\
\text { Avoidance/Rejection) }\end{array}$ & $\begin{array}{l}\text { Child did not comply with the } \\
\text { command and went away }\end{array}$ \\
\hline
\end{tabular}

After observing the caregiver's attitudes that influence the child's discipline behavior, the caregiver received training to improve the knowledge and skills associated with disciplining children. The training comprised four materials (the stages of early childhood development, the way of early childhood learning, parenting style, and disciplinary delivery strategies) and a demonstration of the strategy to discipline children. This training was conducted for 2 days, and the total duration of the training was 4 hours. On the first and second day, the researcher administered a pre-test and post-test question to measure the level of the caregiver's understanding before and after training. This question covered the material obtained by the caregivers during this training. The selection of this material was adjusted to the characteristics of the participants of this study.

To teach strategies for disciplining children, this study focused on educating the caregiver to apply the positive reinforcement technique. To support this technique's implementation, the researcher explained and trained the caregiver to use observation sheets and behavioral records provided by the researcher. The researcher explained the characteristics of the child's eating 
behavior and playing behavior that would be applied by the caregiver. The standard of eating behavior is applied when the child is eating at mealtime and included sitting in a dining chair and not talking while chewing food. The standard of playing behavior was playing during playing time and cleaning up toys. This standard of behavior was adjusted to the development and behavioral needs of the participant in this study.

Next, the researcher asked the caregiver to fill out the reinforcement questionnaire and then determine which form of reinforcement would be given. This reinforcement questionnaire comprised questions related to the form of reinforcement that the child likes, for example, "What type of activities does the child like?" and "What type of object does the child like?" Based on the results of the questionnaire, we concluded that the types of effective reinforcement that should be used were a social reward (praise) and concrete reward (sticker). The stickers consisted of pictures of people who are smiling or sad (emoticon). The child received smile stickers when the expected behavior was observed and sad stickers when the child was observed to not achieve the target of the expected behavior. Provision of the reinforcement occurred after the expected behavior was observed.

Table II. Summary of Training the Trainer

\section{Session 1}

- Caregiver learned about physical, cognitive, and social development in early childhood.

- Researcher conducted a question-and-answer session to explore the caregiver's insights regarding the development of the child she is responsible for.

\section{Session 2}

- Caregiver learned about the materials related to the process of early childhood learning, such as modeling, watching television, punishment, reinforcement, and playing.

- Researcher conducted a debriefing session to explore the caregiver's insight regarding how the child is being cared for.

\section{Session 3}

- Caregiver learned from some materials about four types of parenting patterns: authoritarian, authoritative, permissive, and neglectful.

- Researchers conducted a debriefing session to understand the caregiver's insights regarding the parenting pattern that she used to take care of the child.

\section{Session 4}

- Caregiver received examples of how to convey discipline behavior to children, for example, by providing explanations, singing, playing drama games, 3-2-1 timings, and so forth.

- Researchers conducted a debriefing to explore insights about the impacts of disciplinary strategies implemented by caregiver.

\section{Session 5}

- Caregivers learned about the definitions, conditions, times, and steps to provide positive reinforcement.

- Caregivers fill out the reinforcement questionnaire and determine the type of reinforcement used. 
- Researcher explained the standards of the eating behavior and playing behavior that should be achieved by the child at the end of investigation period and how to record information on the observation sheet and take notes.

- Caregiver demonstrated the discipline of the eating behavior and playing behavior in children.

After the training, the caregiver applied the interventions regarding discipline and positive reinforcement for the child's behavior for 18 days. The intervention phase comprised three parts: baseline phases, intervention phases, and evaluation phases. For the eating behavior interventions, measurements were taken at breakfast and lunch. These times were optimal because the caregiver was responsible for providing assistance during the child's eating activities - from morning to evening. Therefore, provision of the positive reinforcement was carried out in at both times situations to control the consistency of the eating behavior displayed by the child to caregiver. Playing behavior was measured in the afternoon after the child returned home from school.

In the baseline phases, the caregiver did not provide positive reinforcement in response to the child's discipline behavior. Additionally, the researcher observed the caregiver's behavior in applying the discipline to the eating behavior and playing behavior to the child without providing positive reinforcement. In the baseline phases, on the third day, the researcher began to introduce eating and playing rules to the child. To strengthen the regulations, the researcher provided posters displaying the rules for eating and playing that could be used as a reminder for the caregiver and the child at home. The researcher also began assisting the caregiver regarding explanations of when to reward the child with a sticker for the eating behavior and playing behavior, and the application of this intervention began on the first day of the intervention phases. This sticker attachment poster was used for 12 days of the intervention phases.

In intervention phases, the caregiver began to remind the child regarding the standards for the eating behavior and playing behavior on a daily basis. The caregiver began to provide the reinforcement every day. The researcher conducted direct monitoring on the 1st, 3rd, 6th, 9th, and 12th days to determine the development of the positive reinforcement technique applied by the caregiver.

In the evaluation phase, the caregiver began to stop providing reinforcement in response to the child's discipline behavior. The caregiver did not give treatment to the child and recorded only the changes in the child's behavior on the recording sheet provided. The researcher also observed the caregiver's behavior when applying the discipline to the eating behavior and playing behavior after stopping the provision of positive reinforcement to the child.

\section{Analysis}

The data analysis was performed using descriptive analysis by displaying behavioral scores in graphical form. This visual analysis process was used to compare the percentage of the scores for the eating behavior and playing behavior from the baseline, intervention, and evaluation 
phases. The behavioral scores displayed represent the success of the participants in the session.

\section{Results}

Based on the positive reinforcement interventions, the differences in eating behavior scores were observed before and after the intervention. When viewed from the effectiveness of giving positive reinforcement, a gap was observed between the breakfast behavior and lunch behavior. More failures were observed during the breakfast behavior than during the lunch behavior, and the lunch behavior demonstrated the majority of the successes in disciplining the child. Regarding the breakfast behavior, the score range increased from $60 \%$ to $100 \%$ (blue line), and for the lunch behavior, the score range increased from $40 \%$ to $100 \%$ (red line). The following is a general description of the results of eating behavior in children.

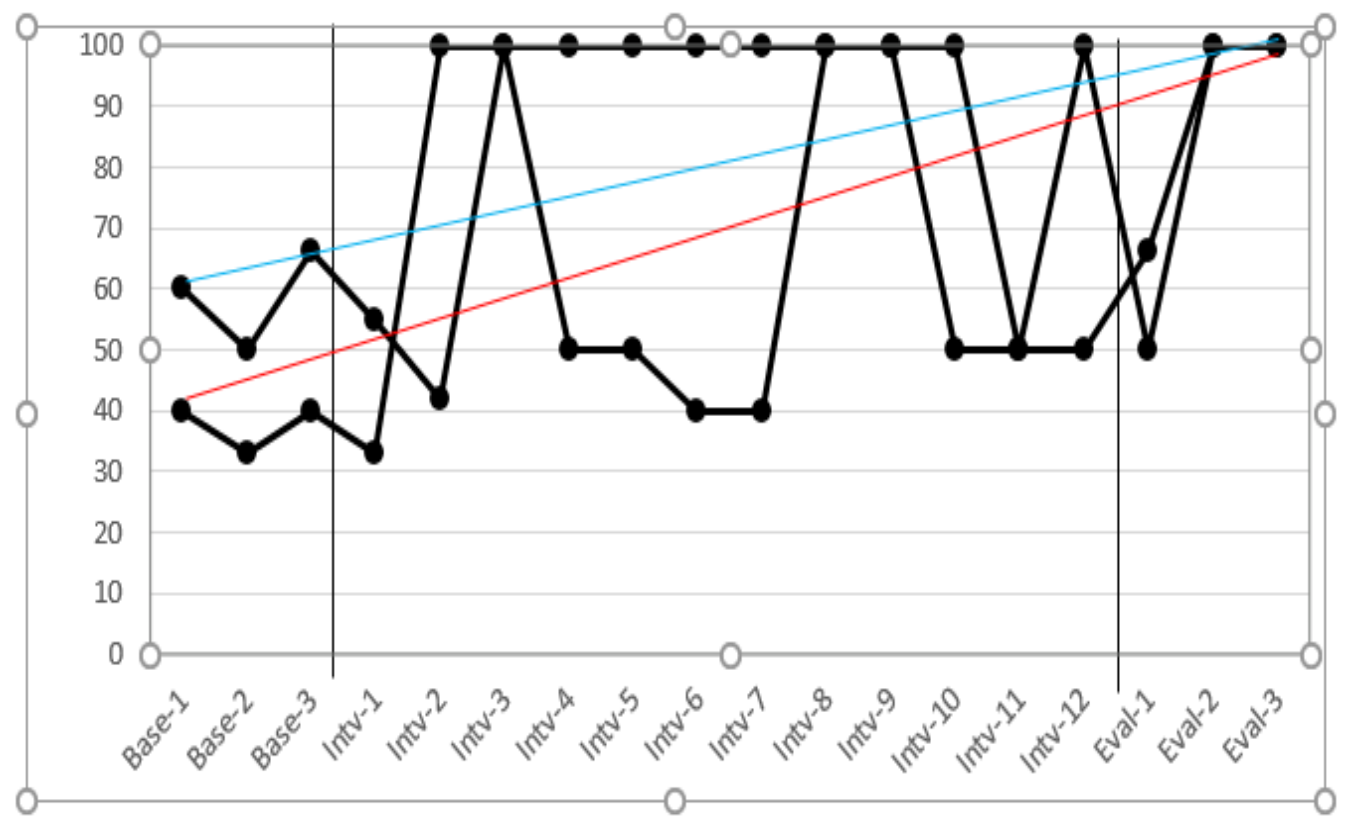

Fig. 1. Percentage discipline in an eating situation

For the breakfast behavior, score fluctuations occurred during the intervention phase. The child's improved behavior in discipline began to occur on the third day of intervention phases, but then a significant decrease in behavior occurred. The re-scoring trend occurred on the 8th day of intervention phases and when it started to enter the baseline phases. 


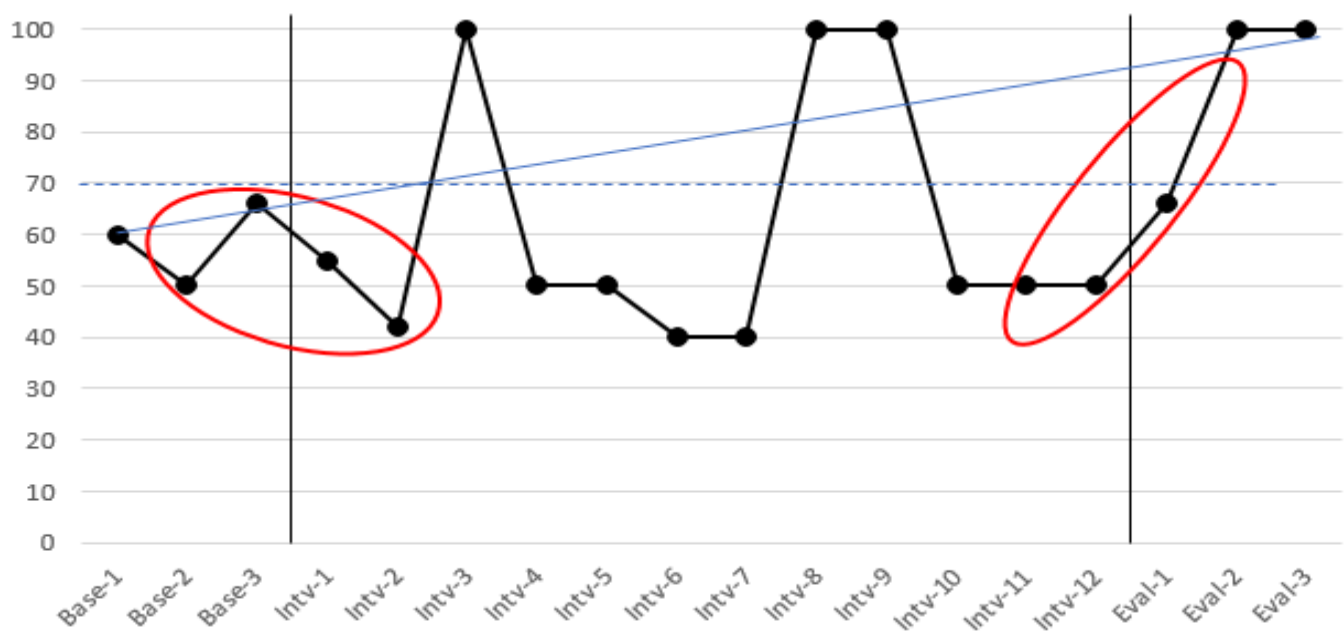

Fig. 2. Percentage discipline in a breakfast setting

For the lunch behavior, the majority of the score charts were quite stable above $70 \%$. Increased disciplinary behavior in the child began to occur on the second day of the intervention phases, although a single drop was observed on the 11th day. It scaled up again on the 2nd day of evaluation phases.

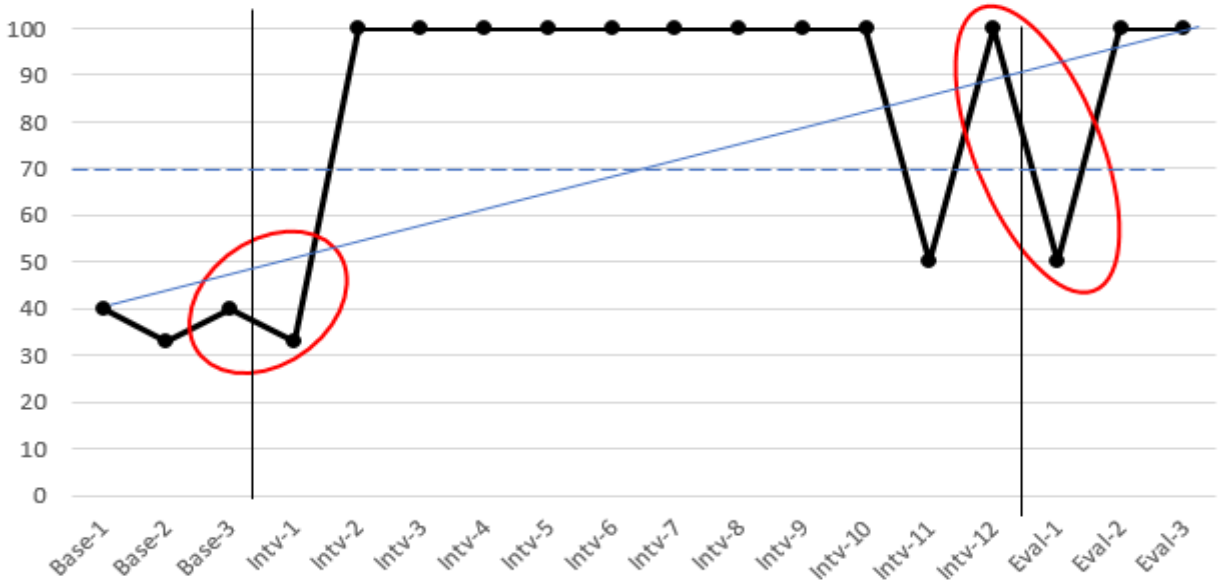

Fig. 3. Percentage discipline in a lunch setting

For the playing behavior, the majority of the score charts are quite stable above $70 \%$. This result means that an increase in child's playing behavior was observed after the positive reinforcement technique was implemented. An increase in playing behavior occurred and began on the first day of the intervention phases; notably, on the second day, a decrease in score was observed. The child's playing behavior remained unchanged from day 3 of the intervention phases to the evaluation session. 


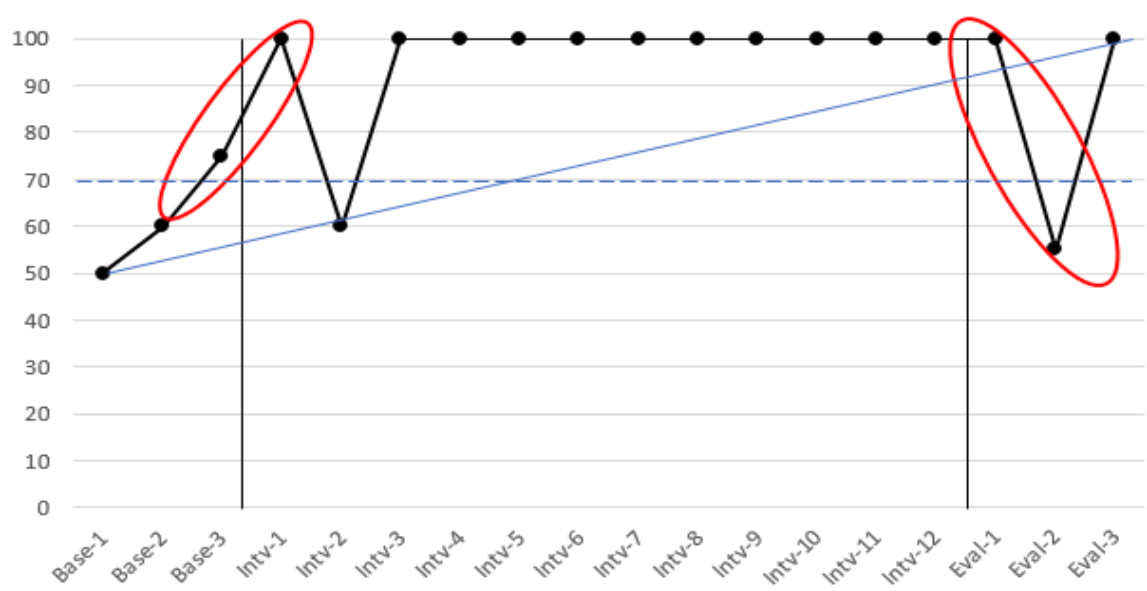

Fig. 4. Percentage discipline in a play setting

\section{Discussion and Conclusion}

In this study, we found that positive reinforcement can increase the discipline of a child while the child is eating or playing. Providing clear rules and appropriate rewards can help children understand the behavior standards of discipline while eating and playing.

According to the result in the breakfast situation, we observed a score fluctuation in terms of increasing discipline behavior because the child was still adapting to the new regulations. From the first day of the intervention session, we observed that the child was unable to comprehend the regulation and the reward. In addition, the role of the caregiver during some of the breakfasts was out of control; thus, the researcher suggests that the caregiver should be replaced by the child's mother. The presence of the mother would affect the effectiveness of providing positive reinforcement during the meal session. The main principles of behavior modification are the consistency of the application of a behavioral contract and the timely provision of the positive reinforcer. The differences in the treatment based on the child's external factors can affect the consistency of the child's behavior.

During lunch, the development of the discipline behavior resulted in consistent improvement because of the caregiver's success with implementing behavioral contracts consistently and providing positive reinforcement immediately after the behavior was observed. In addition, the caregiver was able to control the child's behavior, resulting in decreasing influence from external factors. In one of the interventions and evaluation sessions, the child experienced disciplinary changes due to differences in school schedules. This situation affected the physical condition of the participant; thus, the caregiver had not provided a fair behavioral contract, such as allowing the child to eat lunch on the bed.

In playing situations, the development of child discipline behavior provided consistent improvement. The child understood the standards of behavior that were agreed on in the behavioral contract. The caregiver provided examples of the disciplined behavior in the child by being willing to play at only specified play times and tidying up toys after using them. The 
child was able to learn something from imitating the caregiver's behavior. Therefore, consistent disciplinary treatment from caregivers can be imitated by children.

The success of implementing positive reinforcement was also influenced by the results of the training for the trainer of the caregiver. Thus, providing this intervention technique could help caregivers understand the role of parenting patterns conducted to increase child discipline. In addition, providing training for the trainer also supports caregivers to be capable by implementing positive reinforcement in another situation. In this study, the follow-up results showed the success of the caregiver in the eating and playing situations, supporting the implementation of these interventions in other situations, such as when the child studied. The caregiver provided positive reinforcement by adhering smile stickers to the child's assignment sheet when the child completed the task. In other words, the training of trainers is needed for a person who is significant in the child's life to maintain the emergence of a child's behavior that is targeted in the actual situation.

After the assessment was completed, and before and after the implementation of the positive reinforcement interventions, the caregiver showed an increased awareness in regulating the child's discipline at home. Additionally, the caregiver began to realize the positive influence of setting a meal and play schedule inconsistent with the appearance of an expected discipline behavior. A behavioral contract is one of the critical factors in determining the success of improving the expected behavior because it explains the behavioral criteria to be addressed (Miltenberger, 2010). The caregiver in this study began to be able to determine standards of disciplinary behavior and select appropriate consequences for the child. In addition, the schedule for the provision of the reinforcer and the consistency of the reinforcer forms provided also influenced the emergence of the expected behavior (Martin \& Pear, 2015). In early childhood, children may have learned something by forming habits; thus, environmental factors have a significant effect on their habits.

For further research, we make the following suggestions based on the limitations of this study. First, this study was conducted using one research subject. Therefore, the results of this study have limitations regarding generalizing the results to the general population and adding at least one additional subject to compare the effectiveness of the program is recommended. Second, adding a longer duration for the baseline, intervention, and evaluation phases is necessary to be able to maintain behavior that is more stable. Third, further research can also consider the role of an interpreter in providing assessments to reduce measurement bias. Fourth, we suggest considering an external control when the intervention is carried out in the home setting. For example, by structuring the roles between caregivers and parents to avoid double or overlapping roles during the implementation of the intervention.

In conclusion, this study revealed that positive reinforcement can increase discipline through a caregiver. Discipline behavior in eating and playing settings have been applied successfully with the provision of clear rules and appropriate rewards in accordance with the expected behavior standards. 


\section{References}

Carter, S. L. (2010). A comparison of various forms of reinforcement with and without extinction as treatment for escape-maintained problem behavior. Journal of Applied Behavior Analysis, 43, 543-546.

Feldman, R., \& Klein, P. S. (2003). Toddlers' self-regulated compliance to mothers, caregivers, and fathers: Implication for theories of socialization, Journal of Developmental Psychology, 39, 680-692.

Fraenkel, J. R., \& Wallen, N. E. (2009). How to design and evaluate research in education. $7^{\text {th }}$ ed, New York: McGraw-Hillapproach. The Behavior Analyst Today, 10, 3-4.

Gravetter, F. J., \& Forzano, L. B. (2012). Research Methods for the Behavioral Sciences, 4th ed, Belmont, CA: Wadsworth.

Kusumah, M. A. P. \& Pudjiati, S. R. R. (2017). Increasing compliance and task completion in a child with border intellectual functioning: An application of the behavior modification principle. $1^{\text {st }}$ International Conference on Intervention and Applied Psychology (ICIAP 2017). Journal of Advances in Social Sciences, Education and Humanities Research, 135, 123-135.

Lansford, J. E., Malone, P. S., Dodge, K. A., Chang, L., Chaudhary, N., Tapanya, S., . . . Oburu, P. (2010). Children's perceptions of maternal hostility as a mediator of the link between discipline and children's adjusment in four countries. International Journal Behavior Development, 34, 452-461.

Ma, H. H. (2010). Comparison of the relative effectiveness of different kind of reinforcers: A PEM. The Behavior Analyst Today, 10(3-4), 398-427.

Martin, G., \& Pear, J. J. (2015). Behavior modification: What it is and how to do it, 10th Ed, Upper Saddle River, N.J: Pearson Education, Inc.

Michels, S., Pianta, R. C., \& Reeve, R. E. (1993). Parent self reports of discipline practices and child acting-out behaviors in kindergarten. Early Education and Development, 4, 139-144.

Miltenberger, R. G. (2016). Behavior modification: Principles and procedures, 6th Ed, Belmont, CA: Wadsworth, Cengage Learning.

Nasa, A. F., Pudjiati, S. R. R., \& Tjakrawiralaksana, M. A. (2017). Application of a shaping technique to increase on-task behavior duration in children with ADHD. $1^{\text {st }}$ International Conference on Intervention and Applied Psychology (ICIAP 2017), Journal of Advances in Social Sciences, Education and Humanities Research, 135, 149-165.

Nieman, P., Shea, S., Canadian Paediatric Society, \& Community Paediatrics Committee. (2004). Effective discipline for children. Paediatrics \& Child Health, 9, 37-50.

Phelan as cited in Bowman, J. The program for caregiver to improve discipline sleep nap. Thesis. Universitas Indonesia. 2013

Santrock, J. W. (2011). Educational Psychology, 5th ed. New York: McGraw-Hill.

Santrock, J. W. (2011). Life Span Development, 13th ed. New York: McGraw-Hill.

Smith, A. N. (2004). How do infants and toddlers learn the rules? Family discipline and young children", International Journal of Early Childhood, 36, 27-41.

Wilder, D. A., Normand, M., Atwell, J., \& National Library of Medicine. (2005). Noncontingent reinforcement as treatment for food refusal and associated self-injury. Journal of applied behavior analysis, 38, 549553.

World Health Organization (WHO). (2004). The importance of caregiver-child interactions for the survival and healthy development of young children: A review. Geneva: World Health Organization. Retrieved from http://www.who.int/ iris/handle/10665/42878 